\title{
A visibilidade do trabalho de enfermagem no centro cirúrgico por meio da fotografia*
}

Lucia Helena Reus ${ }^{1}$ JaquelineTittoni ${ }^{2}$

REUS, L.H.; TITTONI, J. The visibility of nursing work in the surgical center through photography. Interface - Comunic., Saude, Educ., v.16, n.41, p.485-97, abr./jun. 2012

This paper originated from a survey conducted among the workers in the surgical center of Hospital de Clinicas de Porto Alegre, Brazil. It analyzed the ways in which the nursing team worked and their relationships with patients and with other healthcare professionals. Foucault's thinking was used, thus emphasizing the links between knowledge and power plays, as well as the effects of truth at work, sustained by these workers' standpoint. The strategy of photography was used from the perspective of intervention research. The surgical center was portrayed as a space for keeping an eye open, surveillance and control. Knowledge is determined from the visibility of bodies, which could be those of patients or workers, and this knowledge is legitimized when it emanates from the brightness of the surgical focus. Studies with photographs allow different viewpoints and create spaces for debates.

Keywords: Surgical center. Work. Power. Intervention research. Photography.
O presente artigo origina-se de uma pesquisa realizada junto aos trabalhadores do centro cirúrgico do Hospital de Clínicas de Porto Alegre, Brasil, analisando os modos de trabalhar da equipe de enfermagem e sua relação com pacientes e demais profissionais da saúde. Utilizou-se o pensamento de Foucault, enfatizando-se as articulações dos jogos de saber e poder, bem como os efeitos de verdade no trabalho, sustentados pelo olhar desses trabalhadores e usando-se a estratégia da fotografia em uma perspectiva da pesquisa-intervenção. O centro cirúrgico foi retratado como um espaço do olhar, da vigilância e do controle. O saber é determinado a partir da visibilidade dos corpos, sejam de pacientes ou de trabalhadores, e este saber é legitimado quando emana do brilho do foco cirúrgico. O trabalho com fotografias possibilitou olhares diversos e a criação de um espaço de discussão.

Palavras-chave: Centro cirúrgico hospitalar. Trabalho. Poder. Estudos de intervenção. Fotografia.

\footnotetext{
- Elaborado com base em Reus (2011) pesquisa aprovada pelo Comitê de Ética do Grupo de Pesquisa e Pós-graduação do Hospital de Clínicas de Porto Alegre. ${ }^{1}$ Psicóloga.

Rua Ramiro Barcelos, 2600, sala 300F. Porto Alegre, RS, Brasil. 90.0350-003

luciareus@terra.com.br

${ }^{2}$ Programa de PósGraduação em Psicologia Social e Institucional, Universidade Federal do

Rio Grande do Sul.
} 


\section{Introdução: a fotografia na pesquisa}
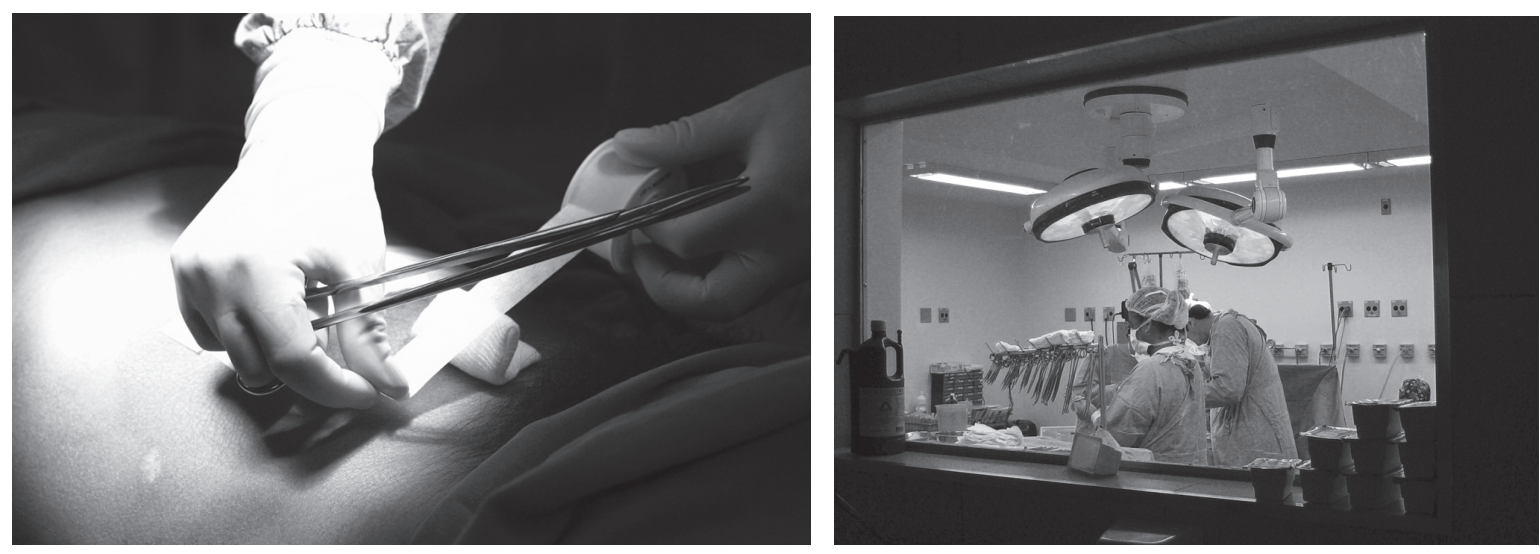

O presente artigo origina-se de pesquisa para dissertação de mestrado realizada junto aos trabalhadores do Centro Cirúrgico do Hospital de Clínicas de Porto Alegre, instituição pública e universitária, integrante da Rede de Hospitais Universitários do Ministério da Educação, e vinculado academicamente à Universidade Federal do Rio Grande do Sul (UFRGS). O projeto foi submetido ao Comitê de Ética desta instituição (GPPG-HCPA). Este estudo teve como objetivo discutir os modos de trabalhar das equipes de saúde e analisar como se articulam os jogos de saber e poder e os efeitos de verdade que possibilitam pensar a ética nos processos de trabalho. Neste artigo, daremos relevância ao trabalho da equipe de enfermagem e sua relação com os pacientes e demais profissionais da saúde do local analisado.

A pesquisa de cunho exploratório e qualitativo está fundamentada nos pressupostos da pesquisa-intervenção, tendo como principal estratégia metodológica a intervenção fotográfica orientada para a análise dos jogos de visibilidade e invisibilidade presentes na definição dos modos de trabalhar das equipes.

A intenção de fazer fotografias em um hospital provocou reações de espanto. Como retratar a dor, o sofrimento, as doenças, os trabalhadores sujos de sangue? Certamente, ideias que levam a uma postura de repúdio a estas imagens dolorosas, imagens que trazem o que não deve ser exposto, o que deve ficar escondido. Neste local, observamos a frequente manipulação de fotografias, que podemos chamar de "técnicas", pois indicam "achados operatórios", como tumores, anormalidades anatômicas, deformidades e curiosidades. Estas fotografias são comuns e recebidas com tranquilidade em um meio onde circulam profissionais de medicina e enfermagem. Encontramos, também, este tipo de fotografia em trabalhos acadêmicos, sempre com a intenção de ilustrar e registrar o que é visualizado no momento da cirurgia ou em procedimentos de enfermagem. Qual é, então, a diferença entre uma fotografia que retrata a imagem técnica de um trabalhador em suas atividades laborais e uma imagem que vai além do que é visto, pois suscita questões e busca compreender, simbolicamente, os sentidos do que é estudado para além de um registro de fatos cotidianos? Benjamin (1994) fala da fotografia como duas instâncias: aquela que diz alguma coisa para a câmera e aquela que diz alguma coisa para o olho; o que é elaborado conscientemente pelo homem e o que aparece num espaço elaborado inconscientemente:

Percebemos, em geral, o movimento de um homem que caminha, ainda que em grandes traços, mas nada percebemos de sua atitude na exata fração de segundo em que ele dá um passo. Só a fotografia revela esse inconsciente ótico, como só a psicanálise revela esse inconsciente pulsional. (Benjamin, 1994, p.94) 
Desse modo, a fotografia traz um novo modo de olhar, fixando um instante, possibilitando a visibilidade sobre detalhes ou um pequeno gesto que, de outro modo, poderia ser imperceptível. Elas nos ensinam um novo código visual, modificam e ampliam nossas ideias sobre o que vale a pena olhar e sobre o que temos o direito de observar, constituindo-se em uma gramática e uma "ética do ver" (Sontag, 2004).

O uso de fotografias em trabalhos de pesquisa na área da saúde é recorrente, seja como forma de ilustrar um evento ou como ferramenta de pesquisa. Um amplo estudo na área de enfermagem identificou produções científicas, nacionais e internacionais, sobre documentação fotográfica de feridas no período entre 1994 e 2007, onde foram encontrados 124 artigos referentes ao tema nos bancos de dados: Medline, oitenta (64,5\%), OVID, 43 (34,6\%), e Lilacs, um (0,8\%). As autoras verificaram que a preocupação com a técnica de fotografar, bem como a utilização de recursos computadorizados foram aspectos importantes nas produções analisadas, tendo a finalidade de fornecer subsídios para o correto tratamento de feridas, reduzindo custos e sofrimento ao paciente (Faria, Peres, 2009).

Esses estudos usam o que podemos qualificar de imagens técnicas. Em outra pesquisa, os autores forneceram câmeras fotográficas a seis gestantes do Hospital Universitário da USP para, em um estudo fotoetnográfico, retratar suas experiências e auxiliar a compreensão do fenômeno saúde-doença: "Os achados demonstraram que a linguagem visual pode favorecer o melhor entendimento dos significados culturais e, com isso, fornecer subsídios para a melhoria do atendimento aos usuários e para a avaliação dos serviços de saúde" (Melleiro, Gualda, 2006, p.82). Este estudo evidencia a análise de imagens, onde as fotografias são qualificadas como linguagem, podendo ser decifradas e discutidas.

Já, na psicologia, podemos constatar que a fotografia torna-se cada vez mais uma alternativa interessante e viável como estratégia metodológica em pesquisas. Tittoni (2004) desenvolveu um trabalho com um grupo de mulheres vinculadas à economia solidária, que trabalham com a confecção de roupas através da reciclagem de retalhos de tecidos. Nesse processo, a utilização do recurso fotográfico teve como objetivo refletir, através da imagem, sobre diferentes aspectos dos modos de viver e trabalhar. A fotografia constitui, assim, uma estratégia de pesquisa que mostrou os jogos de poder, indicando visibilidades e invisibilidades (Tittoni, 2004).

Ainda na área da psicologia social, Osório (2008) desenvolveu estudos junto a trabalhadores da saúde usando também este recurso. Sob a perspectiva teórica da Clínica da Atividade, realizou oficinas de fotografia com trabalhadores de um hospital, propondo que fizessem fotos de situações positivas e negativas para a saúde profissional. Através da discussão das imagens, o trabalhador discute consigo mesmo, com seus pares e com seu objeto de trabalho. Nesse referencial, busca-se a compreensão da relação entre trabalho e subjetividade, não sendo enfocada somente a luta contra o sofrimento, mas a atividade de trabalho como fonte de recriação de novas formas de viver e possibilidades de superação de impasses pelos próprios trabalhadores.

A opção por fotografar cenas de trabalho no centro cirúrgico se insere em uma perspectiva da pesquisa-intervenção, buscando desestabilizar o mito da objetividade na produção do conhecimento e incluindo o pesquisador no campo de investigação. Nessa linha, a "pesquisa-intervenção consiste em uma tendência das pesquisas participativas, que busca investigar a vida de coletividades na sua diversidade qualitativa, assumindo uma intervenção de caráter socioanalítico" (Aguiar, Rocha, 2003, p.66). O que define o caráter desse tipo de pesquisa não é a técnica, e sim a posição que o pesquisador ocupa nos jogos de poder e suas implicações com a instituição do saber científico, desestabilizando-o e favorecendo o coletivo pelo deslocamento do lugar de especialista na análise dos jogos de saber-poder. Assim, sujeito e produção de conhecimento se traduzem em práticas sóciohistóricas, o que torna impróprio o retorno de uma possível neutralidade das práticas de pesquisa (Paulon, Romagnoli, 2010).

Constituindo-se em um processo de trabalho coletivo, ambas, pesquisa-intervenção e fotografia, caminham juntas no acesso às visibilidades. A narrativa fotográfica, como um processo de discussão sobre o conteúdo de imagens, pode ser viabilizada como uma estratégia metodológica que, junto a outros procedimentos, integra uma metodologia de pesquisa, a intervenção fotográfica. Inscrita na perspectiva da pesquisa-intervenção, a intervenção fotográfica é entendida como um processo que implica três momentos cruciais: o acompanhamento dos grupos, com a construção da possibilidade de 
se trabalharem imagens; as oficinas de fotografias, que se constituem em momentos privilegiados de sensibilização do olhar, bem como a produção de imagens; e, por fim, trata-se da narrativa visual, produzida coletivamente (Tittoni, 2009). O que é experienciado pelo grupo na narrativa fotográfica pode ser um acontecimento e pode elucidar diferentes analisadores. Enfim, a intervenção fotográfica constitui uma combinação entre a fotografia e a pesquisa-intervenção, com a intenção de usar a estratégia da fotografia em construções e análises coletivas, aumentando, assim, as possibilidades de se interrogarem e perceberem as linhas de força produzidas no cotidiano das relações.

Neste estudo, para a realização da oficina de sensibilização, os participantes foram convidados por email e cartazes, e a primeira oficina teve como objetivo a apresentação do projeto de pesquisa e a instrumentalização para o trabalho com fotografias. Nesse primeiro encontro, os participantes foram convidados a produzir imagens com o cuidado de não identificarem pessoas, devido a uma orientação do Comitê de Ética na Pesquisa (GPPG-HCPA). No segundo encontro, momento das narrativas fotográficas, a produção de imagens do grupo foi apresentada e discutida, proporcionando a experiência de visualização e reflexão de seu próprio trabalho. Esta intervenção foi finalizada com a realização de uma exposição fotográfica, onde as fotos foram escolhidas pelos autores, impressas e colocadas em um pôster afixado no corredor central do centro cirúrgico, local de grande circulação. Nesta intervenção, juntamente com a apresentação do pôster, em um pequeno texto, as pessoas foram convidadas a manifestarem sua opinião sobre as imagens e a pesquisa, possibilitando, assim, novas reflexões para o estudo.

\section{O centro cirúrgico: espaço do saber pelo olhar}
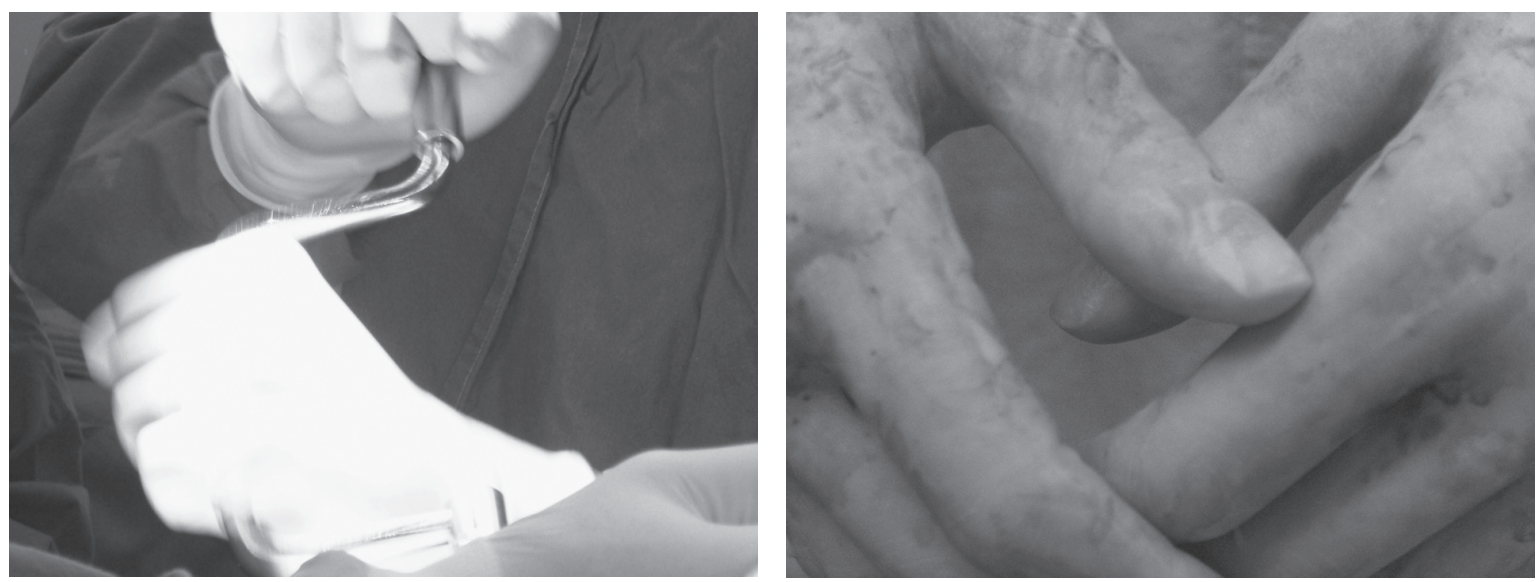

Este estudo foi realizado no centro cirúrgico, que é um local fechado à visitação, fechado à livre circulação e à especulação visual. O que acontece neste local só é revelado aos profissionais que lá trabalham, já que os pacientes vivenciam uma rápida e ficcional passagem em função da anestesia. Esta intervenção realiza um apagamento sensorial, onde se produz o corpo inerte do paciente, sujeito à manipulação cirúrgica sem a consciência dolorosa. Vários profissionais de saúde trabalham em um procedimento cirúrgico e a circulação é intensa. A sala cirúrgica é o local onde se desenvolve a cena e tudo funciona como num filme, onde atores desempenham papéis bem definidos. A cada cirurgia, uma nova refilmagem, onde os atores podem ser diferentes, mas as cenas são repetidas em seus mínimos detalhes. Cada profissional tem um contato diferenciado com o corpo do paciente, o que lhe confere um status nesta relação. O cirurgião trabalha manipulando e modificando o "interior" do corpo, amparado por um saber técnico e acadêmico. Opera, assim, um saber no corpo e no ambiente. O anestesiologista interfere na consciência do paciente, retirando seu acesso ao meio e tornando-o vulnerável aos procedimentos cirúrgicos. Os profissionais de enfermagem trabalham manipulando o "exterior" do corpo, com procedimentos chamados "não invasivos", também amparados por um saber. 
Esses saberes determinam poderes (de olhar e tocar) que, por sua vez, determinam lugares na instituição, processos de subjetivação que moldam a individualidade moderna (Fonseca, 2003).

Por que o centro cirúrgico é um local fechado? As explicações são, num primeiro momento, óbvias e diretas: o local deve ser protegido do risco de contaminações provenientes das pessoas que circulam em outras unidades do hospital e da rua. Assim, a área física deve ser planejada e estruturada levando em consideração essas questões de inacessibilidade. Contudo, há outras questões que, com um olhar mais apurado, também são relevantes: a área física não contempla a visibilidade para o exterior e viceversa. Não é possível que um trabalhador desta unidade olhe para fora do setor, ou um paciente ou familiar tenha acesso visual ao trabalho lá realizado. O que há em um centro cirúrgico além dos profissionais? O que é realizado no interior desta unidade? Existem pessoas doentes, corpos abertos, aberrações anatômicas, tumores, humores, secreções. Olhar o corpo aberto e sendo manipulado envolve outras questões, e entramos para o terreno da ciência, do religioso, do místico, do aterrorizante. Entramos no mundo do desconhecido, do estranho, do inacessível, da escuridão. Podemos, assim, fazer algumas considerações: quando olhamos um corpo, estamos olhando nosso próprio corpo, mas não propriamente nosso corpo como ele é, e sim como o imaginamos, atravessados por sentimentos que estão guardados na memória pela imagem familiar que temos dele. Para Nasio (2009), a imagem não se configura somente no domínio da visão. Além de ser convocada por esse duplo referente a um "original", a imagem não existe senão em um objeto investido afetivamente, inscrito na memória consciente ou inconsciente e capturado nas redes da relação com o outro. A fotografia constitui, para este autor, uma modalidade desta imagem especular, tendo o "poder mágico" de alimentar o amor e o ódio de si. Estas referências nos sugerem questões relativas aos jogos de verdade que envolvem as visibilidades e a ética do olhar para o corpo vulnerável do paciente, entregue à manipulação cirúrgica.

\section{Referentes conceituais: servindo-se do campo foucaultiano para abordar o poder}
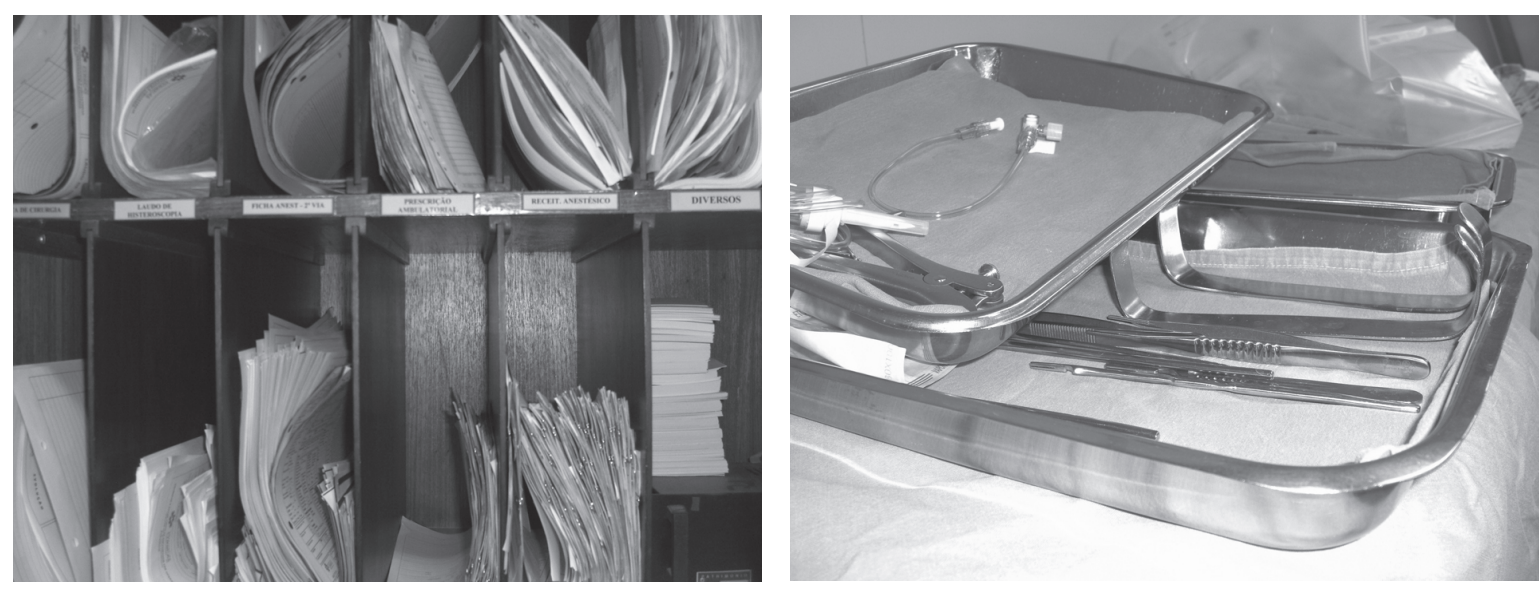

A vigilância é elemento fundamental da disciplina foucaultiana e assume um papel de destaque neste estudo. Apresenta-se na estrutura hierárquica profissional e, até mesmo, na arquitetura, visando a concepção utilitária da ocupação personalizada dos espaços. No centro cirúrgico, o corpo do paciente deve ser constantemente vigiado, preparado, manipulado por todos os profissionais; o corpo do cirurgião deve ser constantemente vigiado pela instrumentadora, em busca de sinais que indiquem quais materiais devem ser fornecidos; o corpo dos técnicos de enfermagem deve ser constantemente vigiado pela supervisão do enfermeiro, enfim, todo um sistema de vigilância que visa permitir e corrigir 
atitudes e intenções. Durante a cirurgia, o corpo do paciente, com a abertura da pele até as camadas mais internas, vai sendo minuciosamente dissecado, olhado e manipulado, constituindo-se em fonte viva de saber.

Foucault inicia "O nascimento da clínica" (1980, p.VII) com a frase: "Este livro trata do espaço, da linguagem e da morte; trata do olhar". Para estudar o saber médico sobre o corpo, ele constrói um minucioso estudo sobre os discursos que constroem e legitimam um saber sobre o corpo, as doenças e a morte, produzindo verdades sobre eles. Esta produção se dá em um jogo de forças definido como um jogo de verdades. Discursos e verdades igualmente são construídos, formando, ao longo do tempo, um discurso científico inabalável e protegido pela supremacia do saber médico.

O olhar sobre o corpo, neste processo, torna-se o fator principal da experiência clínica. Com a morte, doenças foram desvendadas pela anatomia patológica, seguindo uma ordenação do olhar das superfícies até a profundidade dos órgãos, provocando reformulações no nível dos saberes. "A estrutura perceptiva e epistemológica que fundamenta a anatomia clínica, e toda a medicina que dela deriva, é a da invisível visibilidade" (Foucault, 1980, p.190). Com isso, sugere a soberania do visível, do olhar para a geometria de linhas, superfícies e volumes em detrimento dos outros sentidos particulares: o olhar domina todo o campo do saber.

Além da evidente compartimentalização dos exercícios profissionais, longe do que poderíamos chamar de transdisciplinaridade, a hierarquia se mostra explicitamente entre as áreas médicas para com a equipe de enfermagem e, na equipe de enfermagem, entre os enfermeiros e os profissionais de nível técnico. Toda a equipe de enfermagem atua em função de objetivos claros e imperiosos: proporcionar, ao cirurgião, materiais, segurança e apoio no momento da cirurgia. As atividades são planejadas para "entregar", ao cirurgião, o "corpo" a ser trabalhado com a máxima segurança e exposição adequada da área a ser operada. Claramente, isto se reflete na segurança do paciente e no bom andamento da cirurgia, mas o trabalho em sala cirúrgica funciona convergindo para a atuação do cirurgião.

Com as funções assim bem determinadas, ao estilo dos princípios disciplinares foucaultianos, "cada indivíduo no seu lugar; e cada lugar, um indivíduo" (Foucault, 2008, p.123), a disciplina hierárquica nos mostra a configuração da ocupação dos espaços hospitalares. A estrutura arquitetônica e disciplinar possibilita uma visibilidade relativa à vigilância interna, mas age para obstruir a permeabilidade com o exterior. É a arte de dispor os corpos no espaço e no tempo, arranjá-los para produzirem mais e melhor dentro de regras institucionais, circulando em uma rede de relações, sendo, ao mesmo tempo, uma técnica de poder e um processo de saber.

Assim, tomamos as ferramentas conceituais de Foucault para analisarmos as produções de sujeito e verdade. $\mathrm{O}$ autor situa o sujeito como indivíduo falante, vivo, trabalhador, moldado pelo discurso e colocado em relação de produção e significação e em relações de poder (Foucault, 2006a). Nesta perspectiva, Foucault toma o sujeito como uma forma, que pode se modificar dependendo dos diferentes tipos de relações: "Você não tem consigo próprio o mesmo tipo de relações quando você se constitui como sujeito político que vai votar ou toma a palavra em uma assembléia, ou quando você busca realizar o seu desejo em uma relação sexual" (Foucault, 2006a, p.275). Estabelecem-se, assim, diferentes formas de o sujeito reconhecer-se como sujeito na sua relação consigo mesmo e na relação com os outros. Assim, um sujeito se constitui como louco mediante aquele que o declara louco. Um trabalhador é apto para exercer certa profissão mediante os órgãos institucionais e de formação que o declaram enfermeiro, médico ou advogado. Desta forma, os sujeitos se modificam por diferentes condições de sujeição.

Do mesmo modo como os sujeitos se conformam nesta mobilidade, as relações de poder que se estabelecem são igualmente móveis, reversíveis e instáveis. Foucault (2006b) declara não empregar a palavra poder, e sim "as relações de poder", quando cada sujeito procura dirigir a conduta de outro. $\mathrm{O}$ poder está implicado no conceito de dominação, pois exige, na ação, a presença do outro. Para o autor, não se trata de interrogar o poder sobre a sua origem, seus princípios ou seus limites, mas de estudar os procedimentos utilizados, nos diferentes contextos institucionais, para atuar sobre o comportamento dos indivíduos, para formar, dirigir, modificar sua maneira de se conduzir.

A análise das relações saber-poder permite estabelecer a relação entre os sujeitos e os jogos de verdade, e estes, para o autor, se referem ao conjunto de regras de produção de verdade. A questão do 
saber-poder transforma-se em instrumento que permite analisar o problema das relações entre o sujeito e os jogos de verdade. Pela palavra "jogo", nas referências foucaultianas, podemos compreender um conjunto de regras de produção da verdade, que indica certo resultado e que pode ser considerado válido ou não. Repete-se aqui a mobilidade pertinente aos jogos, pois sempre há a possibilidade de mudanças nas regras. Por isso Foucault enuncia: "Quem diz a verdade? Indivíduos que são livres, que organizam um certo consenso e se encontram inseridos em uma certa rede de práticas de poder e de instituições coercitivas" (Foucault, 2006a, p.283). Sendo assim, os jogos de verdades que definem as relações de poder permitem justificar as posições do sujeito e sua mobilidade na estrutura social.

Conforme esta perspectiva, o poder e a liberdade estão articulados pela possibilidade de refletir sobre os jogos de verdade e seus efeitos, através da noção de ética. Para Foucault (2006a), a ética se constitui em uma prática reflexiva da liberdade, em que os códigos morais podem ser pensados e questionados. Onde não há liberdade não existe ética, e faz-se necessária uma distinção sobre a ética e a moral. De acordo com Blondel (1999) apud Nardi (2006), ética e moral têm a mesma origem (do latim, mores e do grego ethos), e ambas se referem à reflexão sobre os princípios que dirigem a ação e que diferenciam o bem do mal. Assim, a moral é tomada como um conjunto de regras e preceitos veiculados pelas instituições prescritoras, como a família, a religião, a escola e o trabalho; e a ética, como o comportamento real dos indivíduos em relação a essas regras e como uma forma privilegiada de reflexão sobre as maneiras de viver. Segundo Schmid apud Nardi (2006), pela via da construção de uma arte de viver, do desenvolvimento de uma estética da existência (estética, aqui, remetida a uma sensibilidade indispensável na reflexão sobre as escolhas do sujeito), os indivíduos podem resistir às formas de dominação.

A ideia desta sensibilidade reflexiva, abordada por Foucault como cuidado de si, remete a um princípio grego fundamental de ocupar-se consigo (epimeléia heautoû), que caracterizou a atitude filosófica ao longo de quase toda a cultura grega, helenística e romana, e que significou um acontecimento no pensamento e na concepção subjetiva do sujeito moderno. O cuidado de si apresenta-se como uma maneira de ser, uma atitude, e como forma de reflexão. Cuidar de si implica munir-se de instrumentos éticos que façam o sujeito refletir sobre regras e princípios que são, simultaneamente, verdades e prescrições. "Cuidar de si é se munir dessas verdades: nesse caso, a ética se liga ao jogo da verdade" (Foucault, 2006a, p.269).

\section{Algumas discussões a partir do processo de produção de imagens: produção de visibilidades}
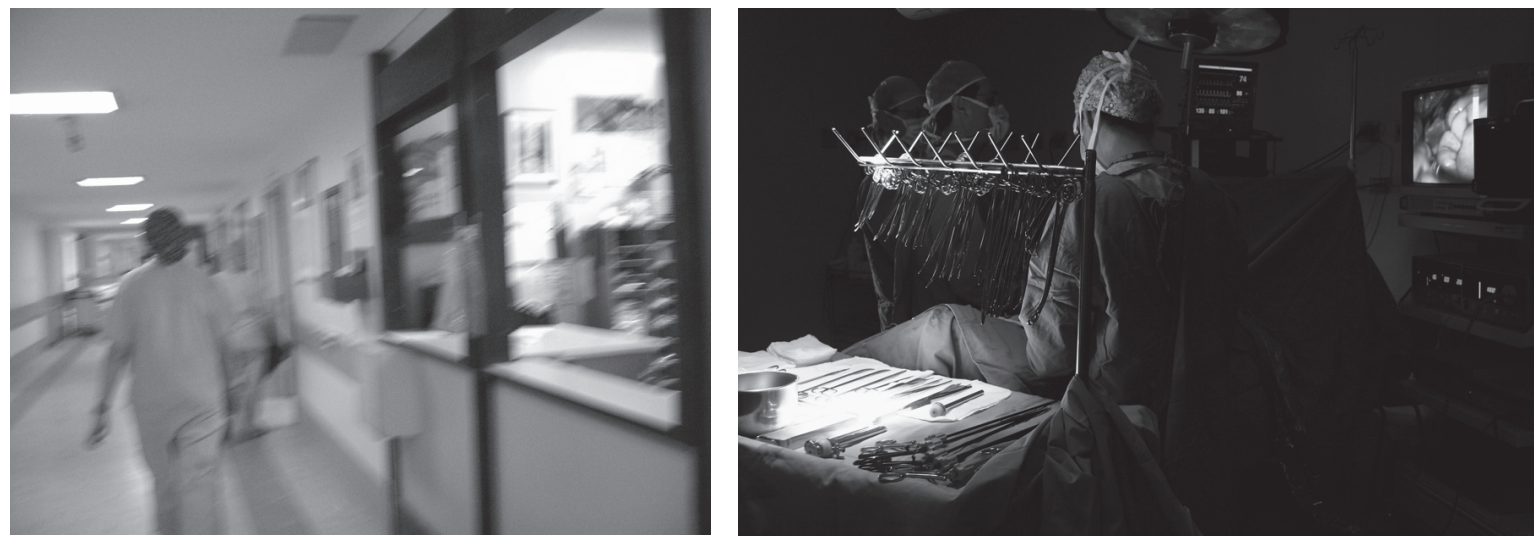

Ao final do estudo, não tivemos a pretensão de fazer um fechamento ou elaborar conclusões, pois pensamos que as questões levantadas evocaram luminosidades que possibilitaram alcançar outras visibilidades e reflexões. Assim, foi possível observar os traços e as marcas que as imagens provocaram 
ao longo das intervenções, bem como pensar de que modo estas visibilidades foram transformadas em questões para o trabalho no centro cirúrgico.

Inicialmente, torna-se importante apontar que a participação espontânea do grupo nas oficinas, em um primeiro convite, foi exclusivamente de enfermeiras, e levou os rumos da pesquisa para um estudo fotográfico dos processos de trabalho emoldurado pelas narrativas destas profissionais. Apesar de a conformação do grupo com poucos participantes ser um fato esperado, é interessante apontar certa resistência à participação em relação a todos os trabalhadores, pois apesar de acharem o estudo interessante, a participação efetiva foi reduzida.

Osório (2002), em um estudo realizado com trabalhadores de hospitais, também constata esta resistência na participação de eventos que se propõem pensar os processos de trabalho, evidenciando, assim, uma modalidade de ação "não institucional" ou uma manobra, até inconsciente, para a preservação de "segredos", onde uma linguagem muito singular é partilhada somente entre os trabalhadores. Além disso, segundo a autora, um local com tantos especialistas tem a tendência a se tornar um local de excesso de verdades.

Assim, por meio das reflexões deste grupo de enfermeiras e exemplificado aqui por algumas de suas falas ${ }^{3}$, o centro cirúrgico foi retratado como um espaço do olhar, da vigilância e do controle. O saber é determinado a partir da visibilidade dos corpos, sejam de pacientes ou de trabalhadores. Estes corpos ocupam lugares bem determinados na escala hierárquica e, como já vimos, determinam técnicas de poder e um processo de saber. Os processos de trabalho estão inseridos neste contexto, seguindo linhas hierárquicas, disposição de corpos no tempo e espaço, bem como a organização de materiais de trabalho, como instrumentais cirúrgicos e equipamentos.

A visibilidade proporcionada pelas fotografias levou a uma percepção da extrema organização que se impõe aos trabalhadores como forma de controlar a grande variedade de elementos presentes no ambiente. Este controle extremado revela o esforço para manter a vida que se encontra em risco constante. A morte, também como o corpo, foi transformada em objeto de saber e enquadrada em um conjunto de regras que a conformam não como o final da doença, mas como fonte de descobertas (Foucault, 1980). O desejo de evitar a morte está presente no controle das pequenas tarefas cotidianas e prescritivas, mas pode se transformar em onipotência se estiver a serviço de um jogo de verdades que visa à legitimação do saber médico como aquele que "imita" Deus.

A sensação de caos esteve sempre presente nas imagens, e parece ser tarefa do enfermeiro lidar com essa contingência. A dinâmica do trabalho é apontada como "trepidante", onde as fotografias com imagens "tremidas" são apontadas como extremamente adequadas por alguns participantes e repelidas por outros. "Tem dias que me sinto assim", foi a frase escrita no pôster de exposição de fotografias, que pode ser qualificado aqui como um analisador e, também, um acontecimento, visto seus desdobramentos. As estruturas em questão são móveis, bem como seus conceitos. Os profissionais passam pelo centro cirúrgico e adquirem o status de sujeito médico, enfermeiro, secretário ou técnico de enfermagem, assim como os pacientes recebem seus aventais e entram no centro cirúrgico para ganharem seu status de paciente operado ou passarem a ser vistos como um órgão doente. As mobilidades presentes nesse processo expõem os poderes que, por sua vez, como vimos, também são móveis. Essa "trepidação" nos modos de trabalhar aparece como uma reverberação luminosa que, a princípio, parece confusa, mas vai indicando um caminho em direção ao foco.

\author{
${ }^{3}$ As falas do \\ grupo pesquisado \\ aparecem entre \\ aspas e identificam \\ o trabalhador por \\ letras maiúsculas \\ escolhidas pela \\ pesquisadora \\ aleatoriamente.
}


${ }^{4}$ Dispositivo arquitetônico de vigilância, em forma de anel, com uma torre central, criado por Bentham e usado por Foucault para estudar o domínio da distribuição de corpos na sociedade disciplinar.
"Temos a impressão que é o barulho que nos atrapalha, que está uma bagunça, que está tudo fora do lugar. Mas não é. Quando tu olhas as fotos, tu vês que não é. É tudo muito organizado, tudo tem o seu lugar". (M)

Olhar os entraves, retratados nas fotos pelas enfermeiras e que desordenam e "trepidam" o andamento do trabalho, trouxe várias questões a discutir. A profissão de enfermagem é voltada ao cuidado do paciente, mas realizada, muitas vezes, de forma gerencial. O estereótipo do profissional que presta cuidados à beira do leito ainda é muito forte, e está ligado a outros estereótipos profissionais, como os da medicina, onde o médico atua no comando e a enfermeira na execução de tarefas. A atuação do enfermeiro no centro cirúrgico é apontada como distante do paciente, conformando-se em um trabalho mais burocratizado e distanciando-se do idealizado. Assim, o trabalho da enfermagem é, essencialmente, voltado para a organização e controle do ambiente, produzindo um esquadrinhamento do tempo e do espaço, onde o corpo é controlado nos gestos e atitudes, expressando um poder (Kruse, 2004).

Neste aspecto, o grupo manifestou seu inconformismo, relatando situações em que as equipes médicas já reclamam da ausência, cada vez maior, da enfermeira em sala cirúrgica, onde deveria prestar cuidados diretos ao paciente. Algumas situações embaraçosas são relatadas, em que a enfermeira se sente "em dívida" com seu atendimento, pois está ocupada resolvendo os "entraves". Na verdade, está resolvendo uma série de situações que fazem parte de seu trabalho de gerenciamento, na qual o telefone é apontado como o fator mais complicado. As enfermeiras são chamadas ao telefone frequentemente para resolver situações diversas, sendo que a maioria é relacionada ao agendamento de cirurgias pelos médicos, como a disponibilidade de sala cirúrgica, horário, disponibilidade de pessoal e outros. Ela é quem recebe, processa e repassa as informações, agindo na "contramão" do panóptico de Bentham ${ }^{4}$, ou melhor, aperfeiçoando-o e disseminando as informações por vias múltiplas e controladas. Deste modo, podemos visualizar a atuação da equipe multiprofissional, que trabalha com um encadeamento de atividades, cada um atuando de maneira controlada, estritamente dentro de suas funções.

O papel da enfermeira é, de certa maneira, o do próprio panóptico, mas com uma dinâmica fluida, como um "olhar divino" que perpassa todos os locais e todas as pessoas. A enfermeira tem esta propriedade de contato com todas as outras esferas profissionais, realizando uma função de controle, vigilância e organização para a otimização das tarefas. Adquire, assim, poder pelo acúmulo de informações, o que se converte em um saber sobre a dinâmica deste trabalho.

Uma questão importante apontada pelo grupo está relacionada às novas exigências institucionais, que trazem um acréscimo nas atividades de registros no computador, atrelando o profissional, cada vez mais, às máquinas.

"Tu faz a assistência e tem que registrar tudo no computador, tu fica muito mais tempo digitando ali o que aconteceu na assistência e o telefone tocando e as pessoas te chamando, então tu demoras mais tempo ali do que na assistência em si". (B) 
É interessante verificar que esta questão constitui um dilema profissional, uma vez que estes "entraves" afastam as enfermeiras do paciente, mas fazem parte da rotina diária de trabalho. Possivelmente sejam atividades desqualificadas pelos profissionais que atuam neste ambiente, pois afastadas dos pacientes, mesmo que vitais para a organização das cirurgias.

Outro aspecto importante é a necessidade de diferenciação dos trabalhadores nos jogos de visibilidades, pois os lugares já estão previamente definidos pela hierarquia. Como ser diferente, se todos usam roupas, toucas e máscaras iguais? Além disso, como diferenciar estruturas anômalas se, anatomicamente, todos somos iguais? As entranhas nos apresentam um triste espetáculo de indiferenciação, que só vem reforçar a "luta pelo lugar ao sol".

A conquista deste espaço só acontece pela diferenciação estratificada em categorias extremamente rígidas de atuação profissional. A ética estabelecida é a da hierarquia praticada, não somente nesta instituição, mas em toda a rede de atendimento de serviços de saúde. Então, podemos pensar que esta estrutura é rígida e não permite flutuações.

Apesar de todos se vestirem com roupas iguais, os médicos transitam por entre os trabalhadores de enfermagem sem o temor de serem confundidos; e, da mesma maneira, os trabalhadores de enfermagem regozijam-se do risco de serem confundidos com os médicos, conformando-se um jogo de visibilidades do imaginário, sustentado pela estrutura hierárquica. Mesmo assim, a luta pela diferenciação é um elemento sempre presente nas discussões do grupo e manifestam um fator de resistência.

Noite pulsão... Na noite os contornos se perdem. Por isso a obscuridade é uma das imagens do desamparo. Lugar do segredo. (Sousa, 2006, p.78)

Em analogia com a câmera escura da câmera fotográfica, sugerida pelo grupo nas oficinas, o centro cirúrgico é apontado como o lugar da indiferenciação, do contato com a imagem crua do corpo. A uniformização visual compele o sujeito na busca de elementos personalizadores que marquem sua presença e seu papel, fugindo do risco de se perder na poeira da envolvente repetição. O risco maior é encontrar este estranho à espreita em cada sala de cirurgia, em cada corpo aberto, em cada peça cirúrgica ou órgão retirado de um paciente. O corpo aberto traz consigo o fator de indiferenciação apontado por Arendt: "monótona mesmice e feiúra penetrante [...] se esse interior aparecesse, todos pareceriam iguais" (apud Ortega, 2008, p.73). Um homem em estado primitivo e exposto ao mundo sem defesas constitui-se em um fantasma que assombra o imaginário e faz com que a busca do mundo palpável e organizado seja ainda mais intensa. Desse modo, como o ambiente tem de ser protegido dos olhares externos, quem está fora também não quer olhar, compondo-se um acordo, de ambos os lados, em não expor essas imagens banalizadoras da carne.

Assim, olhar as imagens sobre o trabalho promoveu, no grupo estudado, o acesso a linhas de visibilidade que despertaram discussões sobre o desejo de uma diferenciação que pudesse extrapolar a lógica hierárquica frente à exposição do corpo aberto.

\section{Para finalizar}

“Um familiar de um doente disse que o hospital era uma máquina de curar. A impressão que o familiar teve foi de que entregavam o paciente em uma porta, de um lado, e nós o devolvemos arrumado e curado do outro; entra por uma porta, ninguém sabe o que acontece lá dentro e tu devolves por outra porta". (M)

A analogia do ambiente de trabalho com a câmara escura ou câmara fotográfica, caixa que deve ser indevassável pela luz e controlada por um operador, é significante e nos faz pensar nas imagens produzidas pelo grupo e seus desdobramentos. Sendo o centro cirúrgico um lugar com acesso restrito somente aos profissionais, ele se converte nesta máquina obscura, máquina de curar. Algo se processa lá, mas poucos sabem o que acontece. Aqueles que estão de fora ficam com esta sensação de máquina 
engolidora de doenças, sem conhecimento do que se passa. Quem está dentro tem de se adaptar à estrutura e não se perder no lugar do desamparo.

O espaço é concebido como efeito das ações prescritivas de acesso e das relações de poder, trazendo uma legitimidade ainda maior aos jogos de verdade. A arquitetura é planejada para permitir um controle interior, articulado e detalhado; um operador, para controlar o comportamento dos que abriga, oferecê-los a um conhecimento, modificá-los, e reconduzindo-os aos efeitos de poder (Foucault, 2008).

A necessidade de artifícios para o reconhecimento do sujeito através do olhar torna-se necessária e, por meio de estratégias simples, como a colocação de espelhos nos lavabos, podem atuar como um instrumento real de visibilidade e reconhecimento. Similar aos espelhos, a função da fotografia como convocação ao olhar e ao reconhecimento ficou bastante evidente nas reações à exposição fotográfica na área central do centro cirúrgico. A identificação dos colegas, de si próprios e de suas especialidades cirúrgicas nas fotografias foi constante. Mesmo nas oficinas, reconhecer alguém ou seu trabalho era comentado e valorizado. A visibilidade perpassou todas as instâncias, mesmo que embaralhada com a cegueira que mostra atitudes de ver e não enxergar, de olhar o saturado e o não relevante. Atitude que mostra, também, que não há um olhar intencional. Nesse sentido, a cegueira branca, proposta por Saramago (1995) em seu livro "Ensaio sobre a cegueira", é constatada e referida pelos participantes da pesquisa em vários momentos em que percebem jamais terem notado algum objeto ou inscrição que aparecem nas fotografias. É a cegueira produzida pelo ato de ver muitas vezes e, assim, tornar o que se vê irrelevante.

O que é então relevante? Motivadas por uma frase apócrifa escrita na exposição fotográfica, a saber, "esta é uma prova viva de estudos irrelevantes", atrevemo-nos a afirmar que é o foco cirúrgico que, por emitir iluminação intensa e brilhante, pode delimitar o que é relevante. Quem trabalha sob essa luminosidade são os cirurgiões. Estão curvados sobre o corpo aberto do paciente e têm a visibilidade total das entranhas, do que é primitivo e do que vive na escuridão do interior do corpo. Os demais saberes gravitam ao redor deste centro de saber-poder, e todos os demais trabalham nesta penumbra de irrelevâncias. Esta penumbra contém outros saberes e poderes, mesmo que não legitimados pela soberania do olhar médico e científico.

Assim, este estudo se debruçou sobre os elementos que gravitam ao redor, que estão na obscuridade e fora do foco iluminado. As fotografias possibilitaram um olhar que se sobressai à cegueira do trabalho cotidiano, que lança luz à penumbra do trabalho secundário e que questiona o dentro e o fora. Tanto essa cegueira como o brilho são instâncias que fazem parte de um jogo de forças, são estratégias dos jogos de verdade. Todavia, são encaradas como naturalizadas, pois incorporadas no cotidiano de trabalho e não visualizadas. A visibilidade desses jogos pode adquirir novas possibilidades através do olhar fotográfico, com suas táticas de congelamento no tempo, possibilidades de olhares diversos e de criação de um espaço de discussão.

Verificamos, portanto, que a estratégia metodológica utilizada beneficiou sobremaneira este estudo, de modo a pensarmos que, sem ela, sua realização teria se tornado mais árdua. O trabalho com imagens possibilitou a evocação do trabalho real, trazendo situações do cotidiano que puderam ser questionadas e discutidas. Essa escolha privilegiou o olhar, assim como a clínica investigada por Foucault (1980), que mudou a estrutura através dos tempos, com a substituição da expressão o que é que você tem por onde Ihe dói, proferida pelo médico a seu paciente. Em um local de difícil acesso a luminosidades estrangeiras, as imagens despertaram sentidos, possibilitaram reflexões que, de outra forma, talvez, ficassem engessadas nas malhas do discurso institucional.

\section{Colaboradores}

As autoras participaram igualmente de todas as etapas de elaboração do manuscrito. 


\section{Referências}

AGUIAR, K.F.; ROCHA, M.L. Pesquisa-Intervenção e a produção de novas análises.

Psicol. Cienc. Prof., v.23, n.4, p.64-73, 2003.

BENJAMIN, W. Pequena história da fotografia. Obras escolhidas: magia e técnica, arte e política. São Paulo: Brasiliense, 1994. v.1.

FARIA, N.G.F.; PERES, H.H.C. Análise da produção científica sobre documentações fotográficas de feridas em enfermagem. Rev. Eletr. Enf., v.11, n.3, p.70411, 2009. Disponível em: <http://www.fen.ufg.br/revista/v11/n3/v11n3a31.htm>. Acesso em: 24 nov. 2009.

FONSECA, M.A. Michel Foucault e a constituição do sujeito. São Paulo: EDUC, 2003.

FOUCAULT, M. A ética do cuidado de si como prática da liberdade. In: (Org.).

Ditos e escritos IV: ética, sexualidade, política. 2.ed. Rio de Janeiro: Forense Universitária, 2006a. p. 264-288.

Foucault. In: (Org.). Ditos e Escritos IV: ética, sexualidade, política. 2.ed. Rio de Janeiro: Forense Universitária, 2006b. p.234-9.

Vigiar e punir. 35.ed. Petrópolis: Vozes, 2008.

O nascimento da clínica. 2.ed. Rio de Janeiro: Forense Universitária, 1980.

KRUSE, M.H.L. Os poderes dos corpos frios: das coisas que ensinam às enfermeiras. Brasília: ABEn, 2004.

MELLEIRO, M.M.; GUALDA, D.M.R. A abordagem fotoetnográfica na avaliação de serviços de saúde e de enfermagem. Texto Contexto Enferm., v.15, n.1, p.82-8, 2006.

NARDI, H.C. Ética, trabalho e subjetividade. Porto Alegre: Ed. da UFRGS, 2006.

NASIO, J.D. Meu corpo e suas imagens. Rio de Janeiro: Jorge Zahar, 2009.

ORTEGA, F. O corpo incerto. Rio de Janeiro: Garamond, 2008.

OSÓRIO, C. Oficina de fotos: uma atividade para re-inventar a atividade de trabalho. In: SEMINÁRIO NACIONAL DE SAÚDE MENTAL E TRABALHO. Oficina 1: Saúde mental e trabalhadores da saúde. São Paulo, 2008. Disponível em: http://www.fundacentro.gov.br/dominios/CTN/anexos/Oficina\% 201\%20\%20Claudia\%200srio\%20da\%20Silva\%20_texto_.pdf Acesso em: 11 jan. 2011.

. Vida de hospital: a produção de uma metodologia para o desenvolvimento da saúde do profissional de saúde. 2002. Tese (Doutorado) - Fundação Oswaldo Cruz, Escola Nacional de Saúde Pública, Centro de Estudos em Saúde do Trabalhador e Ecologia Humana, Rio de Janeiro. 2002.

PAULON, S.M.; ROMAGNOLI, R.C. Pesquisa intervenção e cartografia: melindres e meandros metodológicos. Estud. Pesqui. Psicol.. v.10, n.1. p.85-102, 2010. Disponível em: <http://www.revispsi.uerj.br/v10n1/artigos(pdfv10n1a07.pdf)>. Acesso em: 13 set. 2010

REUS, L.H. Da câmara escura ao brilho do foco: visibilidades possíveis dos trabalhadores de centro cirúrgico. 2011. Dissertação (Mestrado) - Programa de Pós Graduação em Psicologia Social e Institucional, Universidade Federal do Rio Grande do Sul, Porto Alegre. 2011.

SARAMAGO, J. Ensaio sobre a cegueira. São Paulo: Companhia das Letras, 1995.

SONTAG, S. Sobre fotografia. São Paulo: Companhia das Letras, 2004.

SOUSA, E.L.A. Noite e dia e alguns monocromos psíquicos. Rev. Depart. Psicol. - UFF, v.18, n.1, p.77-86, 2006. 
TITTONI, J. Sobre psicologia e fotografia. In: (Org.). Psicologia e fotografia: experiências em intervenções fotográficas. Porto Alegre: Dom Quixote, 2009. p. 7-23. Saúde mental, trabalho e outras reflexões sobre a economia solidária. In: $\overline{M E R L O}$, A.R.C. (Org.). Saúde e trabalho no Rio Grande do Sul. Porto Alegre: Ed. UFRGS, 2004. p.65-93.

REUS, L.H.; TITTONI, J. La visibilidad de la enfermería en el centro quirúrgico a través de la fotografía. Interface - Comunic., Saude, Educ., v.16, n.41, p.485-97, abr./jun. 2012.

Se presentan los resultados de una investigación con trabajadores del centro quirúrgico del Hospital de Clínicas de Porto Alegre, Brasil, sobre el trabajo de la enfermería y su relación con pacientes y otros profesionales de salud. Las ideas de Foucault fueron las basis teóricas del estudio con énfasis en las articulaciones de los juegos de saber y poder, los efectos de la verdad en el trabajo, sostenidos por la mirada de estos trabajadores, usando la estrategia de la fotografía en una perspectiva de investigación interventiva. El centro quirúrgico fue retratado como un lugar para la mirada, vigilancia y el control. El conocimiento es determinado por la visibilidad de los cuerpos, sean pacientes o trabajadores, y este conocimiento se justifica cuando emana del brillo del foco quirúrgico. Con el trabajo de fotografías se hizo posible conjeturar distintas miradas y crear un espacio para el debate.

Palabras clave: Servicio de Cirurgía em Hospital. Trabajo. Poder. Estudios de intervención. Fotografía. 
